\title{
Mor İdrar Torbası Sendromu: Nadir Bir Klinik Olgu
}

\author{
Purple Urine Bag Syndrome: A Rare Clinical Case
}

\author{
Muzaffer MIZRAK ${ }^{1}$, Özgün YETKIN MIZRAK², Nevreste ÇELiKBiLEK ${ }^{3}$, Emel BAŞAR ${ }^{4}$, \\ Mustafa KOCAAĞA ${ }^{1}$ \\ 1 Sağlık Bilimleri Üniversitesi, Ankara Eğitim ve Araştırma Hastanesi, Tıbbi Mikrobiyoloji Bölümü, Ankara. \\ ${ }^{1}$ Health Science University, Ankara Training and Research Hospital, Department of Medical Microbiology, Ankara, Turkey. \\ 2 Ankara Bilkent Şehir Hastanesi, Nöroloji Kliniği, Ankara. \\ ${ }^{2}$ Ankara Bilkent City Hospital, Department of Neurology, Ankara, Turkey. \\ ${ }^{3}$ Ankara Bilkent Şehir Hastanesi, Tıbbi Mikrobiyoloji Bölümü, Ankara. \\ ${ }^{3}$ Ankara Bilkent City Hospital, Department of Medical Microbiology, Ankara, Turkey. \\ ${ }^{4}$ Elmadağ Dr. Hulusi Alataş Devlet Hastanesi, Nöroloji Kliniği, Ankara. \\ ${ }^{4}$ Elmadağ Dr. Hulusi Alataş State Hospital, Department of Neurology, Ankara, Turkey.
}

Makale Atıfı: Mızrak M, Yetkin Mızrak Ö, Çelikbilek N, Başar E, Kocaağa M. Mor idrar torbası sendromu: nadir bir klinik olgu. Mikrobiyol Bul 2019;53(4):457-463.

\section{ÖZ}

Mor idrar torbası sendromu (MiTS) idrar sondasında bakteriyel kolonizasyona bağı indigo (mavi) ve indirubin (kırmızı) pigment üretimiyle karakterize nadir görülen bir klinik durumdur. MiTS patogenezinde, triptofandan çeşitli metabolik yolaklar sonucu bu iki pigmentin üretilmesi rol oynar. Triptofan deaminasyonla indole çevrilir, indol karaciğerde konjugasyonla indoksil sülfata çevrilir ve indoksil sülfat da idrara geçerek atılır. Providencia stuartii ve Providencia rettgeri, Klebsiella pneumoniae, Proteus mirabilis, Escherichia coli, Enterococcus spp., Morganella morganii, Pseudomonas aeruginosa, Citrobacter spp. ve B grubu streptokok gibi sülfataz ve fosfataz üreten bakteriler idrar ile atılan indoksil sülfatı indoksile parçalar. İndoksilin oksidasyonu sonucu indigo (mavi) ve indirubin (kırmızı) pigmentleri açığa çıkar. Bu pigmentler polivinil klorür (PVC) içeren üriner kateter ve plastik bir idrar torbası ile temas ettiğinde, idrarda mor renk değişikliği görülür. İdrarda renk değişikliği; hematüri, üriner sistem tümörleri ve ilaç yan etkileri gibi birçok patolojik durumun ayırıı tanısında çok önemli bir klinik belirti olup hastalar, hasta yakınları ve sağık çalışanları için endişe verici olabilmektedir. İdrarda mor renk değişikliği literatürde nadir olarak bildirilmiştir ve çoğunlukla üriner sistem enfeksiyonları ile ilişkili bulunmuştur. Bu olguda; özgeçmişinde hepatit B, kronik konstipasyon ve kronik böbrek yetmezliği nedeniyle hemodiyaliz öyküsü olan 60 yaşında kadın hasta akut intraserebral hemoraji tanısıyla nöroloji kliniğine yatırıımıştır. Hastanın nörolojik muayenesinde konfüzyon ve sağ hemipleji saptanmıştır. İmmobilizasyon nedeniyle idrar sondası uygulanan hastanın yatışının 10. gününde idrarın kırmızı renk aldığı görülmüşsür. Bu renk değişikliğinin hematüri olduğu düşünülmesine rağmen yapılan idrar tetkikine göre hematüri kaynaklı olmadığı anlaşılmıştır. Daha sonra iki gün içinde idrarda mor renk değişikliği görülen hastanın ateşinin de olması üzerine tam kan sayımı, biyokimyasal tetkikler, kan ve idrar kültürleri gönderilerek ampirik piperasilin-tazobaktam ve teikoplanin tedavisi başlanmıştır. İdrar kültüründe Enterococcus faecalis izole edilmiş ve koloni sayısı $10^{5} \mathrm{cfu} / \mathrm{ml}$ olarak saptanmıştır. Antibiyotik duyarılıı sonuçlarına göre piperasilin-tazobaktam kesilerek tedaviye meropenem eklenmiştir. Ayrıca

Iletişim (Correspondence): Dr. Muzaffer Mızrak, Sağlık Bilimleri Üniversitesi, Ankara Eğitim ve Araştırma Hastanesi, Tıbbi Mikrobiyoloji Bölümü, 06230, Altındağ, Ankara, Türkiye. Tel (Phone): +90 50556141 07, 
hastanın kabızlığı için diyeti düzenlenerek hastaya sıvı replasmanı yapılmış ve laksatif tedavi verilmiştir. Tedaviden sonra kabızlığı gerileyen hastanın idrar rengi düzelmiş ve ardından alınan idrar kültürlerinde üreme saptanmamışır. Bu olguda olduğu gibi kronik konstipe, üriner kateterizasyon uygulanmış, idrar yolu enfeksiyonu ve renal disfonksiyonu olan hastalarda MiTS gelişebileceği akılda tutulmalıdır.

Anahtar kelimeler: Mor idrar torbası sendromu; indigo; indirubin; Enterococcus faecalis; üriner sistem enfeksiyonu.

\section{ABSTRACT}

Purple urine bag syndrome (PUBS) is a rare syndrome characterized by production of indigo (blue) and indirubin (red) pigments due to bacterial colonization in urinary catheter. The pathogenesis of PUBS is related to the combination of these two pigments produced from the metabolism of tryptophan. Tryptophan turns into indole by deamination, indole turns into indoxyl sulphate by hepatic conjugation and indoxyl sulphate is secreted into urine. Sulphatases and phosphatases enzymes produced by bacteria like Providencia stuartii and Providencia rettgeri, Klebsiella pneumoniae, Proteus mirabilis, Escherichia coli, Enterococcus spp., Morganella morganii, Pseudomonas aeruginosa, Citrobacter spp. and group B streptococci convert indoxyl sulphate to indoxyl. In the urinary tract, oxidation of indoxyl results in the production of indigo and indirubin pigments. These pigments react with polyvinyl chloride (PVC) lining of the urinary catheter bag and the reaction results purple discoloration of urine. Urine discoloration is very important clinical sign in the differential diagnosis of several pathological conditions such as hematuria, urinary system tumors and drug side effects and may be disquieting for patients, families and healthcare workers. Purple urine discoloration is rarely reported in the literature and it is generally associated with urinary tract infection. In this report, a 60 years old woman with a past medical history of significant chronic kidney disease undergoing regular hemodialysis, chronic constipation and hepatitis B was admitted to our neurology clinic because of acute intracerebral hemorrhage. She had confusion and right hemiplegia in her neurological examination and required urinary catheterization due to immobilization. Red coloration was observed in urine on the tenth hospital day. Although this coloration was thought to be hematuria, according to urine examination it was not hematuria. Then urine color turned into purple within two days. The next day, because of fever, full blood count and other blood investigations were performed and urine was sent to the laboratory for culture. Empirical piperacillin-tazobactam and teicoplanin antibiotic treatments were commenced. In the urine culture, $10^{5}$ $\mathrm{cfu} / \mathrm{ml}$ Enterococcus faecalis was isolated. According to the antibiotic susceptibility results the therapy was changed and meropenem was added to the treatment. For her constipation, supportive managements such as hydration, nutrition and laxative treatment were applied. After all the treatments, the patient's constipation regressed, the urine had become normal colored and the following urine cultures were not revealed any bacterial growth. As in this case, when the urine discoloration occurs, PUBS should be kept in mind which is especially seen in elderly female patients with chronic constipation, urinary catheterization, urinary tract infection and renal failure.

Keywords: Purple urine bag syndrome; indigo; indirubin; Enterococcus faecalis; urinary tract infection.

\section{Giriş}

Mor idrar torbası sendromu (MiTS) genellikle kronik konstipe, kalıcı üriner kateterizasyonlu ileri yaştaki kadınlarda görülen, üriner kateterde bakteri kolonizasyonuna bağlı indigo (mavi) ve indirubin (kırmızı) pigment üretimi sonucunda idrarın mor renk almasıyla karakterize nadir görülen bir sendromdur. MiTS; hastalar, hasta yakınları ve sağlık çalışanları için endişe verici bir durum olabilmektedir ${ }^{1-3}$.

MiTS ilk olarak 1978 yılında Barlow tarafından tanımlanmıştır ${ }^{1}$. MiTS; yaşlı olmak, kadın cinsiyet, immobilizasyon, konstipasyon, kronik üriner kateterizasyon, alkali idrar, üri- 
ner enfeksiyon ve böbrek yetmezliği gibi risk faktörleriyle ilişkilidir. Pseudomonas aeruginosa, Proteus mirabilis, Providencia spp., Escherichia coli, Klebsiella pneumoniae, Morganelli morganii, Citrobacter spp., metisiline dirençli Staphylococcus aureus, grup B streptokoklar ve Enterococcus spp. MiTS hastalarından yaygın olarak izole edilen bakteri türleridir ${ }^{1-5}$.

MiTS'in patogenezinde konstipasyonu olan hastalarda diyetle alınan triptofanın bağırsak mikrobiyotasındaki bakteriler tarafından indole deaminasyonu rol oynar. Daha sonra indol karaciğerde konjugasyonla indoksil sülfata çevrilir. İdrara sekrete edilen indoksil sülfat üriner kateterde kolonize bakteriler tarafından sülfataz ve fosfataz enzimleri aracılığıyla indoksile dönüştürülür. İndoksilin oksidasyonu sonucu indigo (mavi) ve indirubin (kırmızı) pigmentleri meydana gelir. Alkali idrar oksidasyonu hızlandırır. Bu pigmentler plastik bir idrar torbası ile temas ettiğinde, idrar torbasında mor bir renk meydana getirir. Indikatörler idrarda kendi başlarına mor bir renk vermezken, havaya maruz kaldıklarında hem indigo (mavi) hem de indirubin (kırmızı) oluşturmak üzere oksitlenirler ve polivinil klorür (PVC) içeren plastiklerle reaksiyona girerek idrar torbasındaki mor rengi oluşturur$\operatorname{lar}^{2-7}$.

Altta yatan risk faktörlerini kontrol altına almak, üriner kateterin değişimi, uygun üriner antisepsisi ve semptomatik üriner sistem enfeksiyonu olan hastalarda antibiyotik tedavisi MiTS tedavisinde alınması gereken önlemlerdir ${ }^{1,2,7-9}$.

Bu raporda, özgeçmişinde kronik böbrek yetmezliği öyküsü olan, immobilize, kronik konstipasyonlu, nadir bir klinik durum olarak görülen mor idrar torbası sendromu tanısı alan kadın olgu sunulmuştur.

\section{OLGU SUNUMU}

Özgeçmişinde hipertansiyonu, kronik böbrek yetmezliği olan ve haftada üç kez rutin hemodiyalize giren 60 yaşında kadın hasta acil servise konuşma bozukluğu, sağ kol ve bacakta kuvvetsizlik şikayetleriyle başvurdu. Hastanın nörolojik muayenesi yapıldığında genel durumu kötü, bilinç uykuya meyilli ve non-koopere bulundu. Hastada sensörimotor afazi, sağ santral fasiyal paralizi, sağ üst ekstremitede pleji, sağ alt ekstremitede motor kuvvette azalma saptandı. Hastanın yapılan kraniyal görüntülemesinde intraserebral hemoraji saptandı. Beyin tomografisinde sol talamus düzeyinde $31 \times 18 \mathrm{~mm}$ boyutunda hipertansif kanama ile uyumlu parankimal hematom görüldü. Tanımlı hematomun ventriküler sisteme açıldığı izlendi ve hastanın nöroloji kliniğine yatışı yapıldı. İmmobilize olan hastaya aynı gün içinde Foley üriner kateter takıldı. Bir hafta sonra idrarının kırmızı renk aldığı görülen hastada hematüri düşünüldü ancak yapılan tam idrar tetkikinde hemoglobin: negatif, pH: 9, lökosit sayısı: 5/HPF, eritrosit sayısı: 4/HPF, bakteri: 2636/HPF olarak saptandı (Resim 1). Bu belirtiden iki gün sonra idrar torbasındaki idrarının mor renk aldığı görüldü (Resim 2). Hastanın anamnezi sorgulandığında daha önce bu tarz bir renk değişikliği olmadığı, hastaya daha önce hiç Foley üriner kateter takılmadığı ve hastada iki haftadır dışkılama olmadığı öğrenildi. Yapılan muayenede batında hafif distansiyon görülürken hassasiyet, defans ya da "rebound" saptanmadı. Rektal tuşede bol 


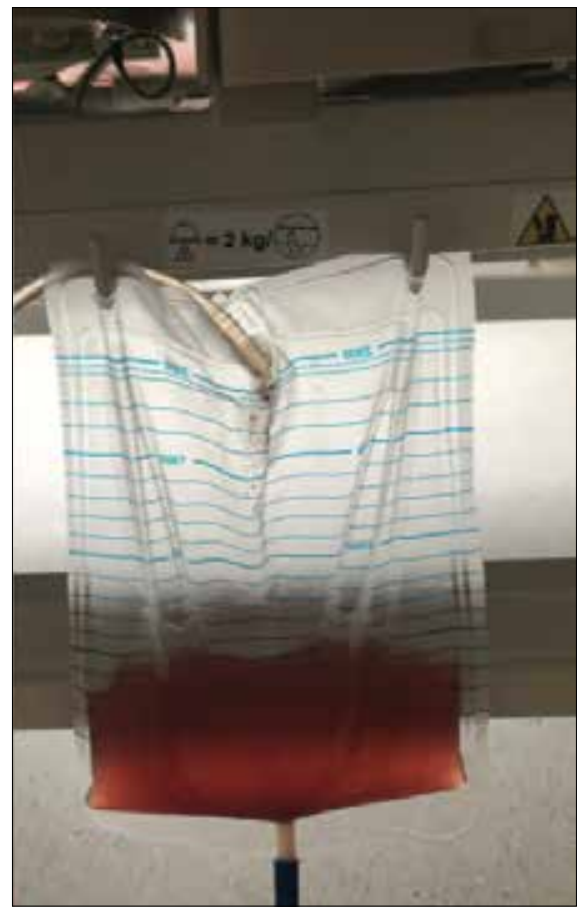

Resim 1. Bir hafta sonra hastanın idrarında görülen kırmızı renk değişikliği.
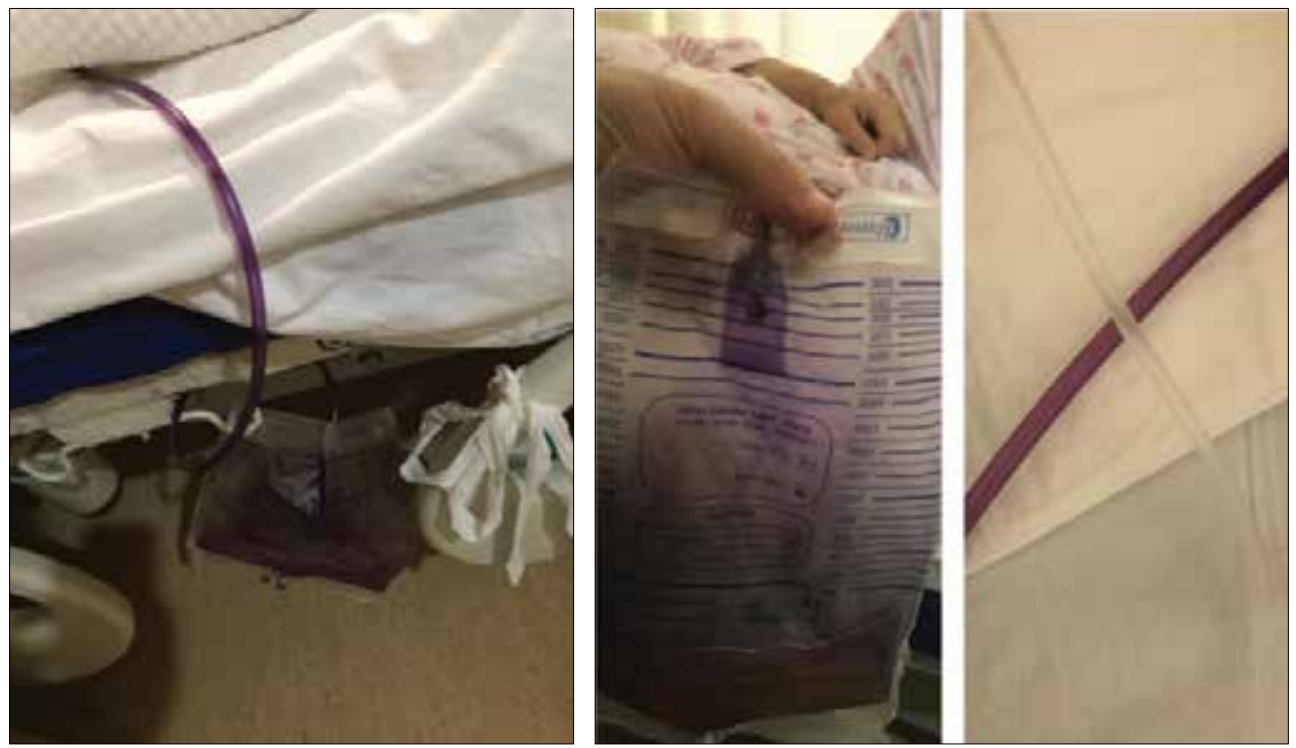

Resim 2. Idrarda kırmızı renk değişikliğinden sonra görülen mor renk değişikliği. 
miktarda fekalit tespit edildi. Hastanın takiplerinde ateş yüksekliği olması üzerine kan ve idrar kültürleri alındı. İdrarında kırmızı renk değiş̧ikliği nedeniyle hematüri düşünülerek TiT gönderildi ve sonucunda idrarda hemoglobin ve eritrosite rastlanmadı. Ampirik piperasilin-tazobaktam ve teikoplanin tedavisi başlandı. Kan kültürü şişeleri Bactec 9240 (Becton Dickinson, Maryland, ABD) cihazına yüklendi. Steril idrar kabında gönderilen örnek hafifçe çalkalandıktan sonra idrar örneğinin dip kısmından $0.001 \mathrm{ml}$ kalibre öze ile alınarak koyun kanlı ve "eosin methylene blue (EMB)" agara kantitatif yöntem ile ekildi. Plaklar 24 saat süreyle $35-37^{\circ} \mathrm{C}^{\prime}$ de etüvde inkübe edildikten sonra üreme açısından kontrol edildi. Koyun kanlı agarda $10^{5} \mathrm{cfu} / \mathrm{ml}$ miktarda saptanan üremenin ardından kolonilerden yapılan Gram boyamada gram-pozitif koklar görüldü. Katalaz testi negatif, L-Pirolidonil Aminopeptidaz (PYR) testi pozitif olan üremeler API Rapid ID 32 Strep sistemi (bioMerieux, Fransa) ile Enterococcus faecalis olarak tanımlandı. Kültür sonucuna göre piperasilin-tazobaktam kesilerek tedaviye meropenem eklendi. Periferik kan kültüründe üreme saptanmadı. Hastanın tedavi sonrası altıncı ve dokuzuncu gün kontrol idrar kültürlerinde üreme saptanmadı. Hastanın konstipasyon şikayetine yönelik laksatif tedavi verilerek diyet düzenlemesi yapıldı. İdrar yolu enfeksiyonu tedavi edilen hastanın idrar rengi iki üç gün içinde giderek düzeldi ve tamamen normal rengine döndü.

\section{TARTIŞMA}

MiTS tek başına iyi seyirli bir klinik tabloya sahip olmasına rağmen, altta yatan patolojik faktörlerin ve üriner sistem enfeksiyonunun önemli bir morbidite ve mortalite nedeni olmasından dolayı akılda tutulması gereken klinik bir sendromdur ${ }^{1,3,5-7}$.

Literatürde eşlik eden konstipasyonu, immobilizasyonu, kronik böbrek yetmezliği, üriner kateterizasyonu ve üriner enfeksiyonu olan ileri yaş hastalarda MiTS olguları bildirilmiştir. Al Montasir ve arkadaşları ${ }^{1} 2013$ yılında 86 yaşında osteoporoz ve bilateral femur boyun fraktürü nedeniyle immobilize olmuş kadın hastada MiTS geliştiğini bildirmişlerdir. Bu durumu hastanın altta yatan kronik konstipasyonuna ve üriner sistem enfeksiyonuna bağlamışlardır. Hastanın idrar analizinde alkali idrar tespit edilmiş ve idrar kültüründe E.coli izole edilmiştir. Ayrıca kronik konstipasyona bağlı olarak bağırsakta aşırı bakteriyel çoğalma nedeniyle gastrointestinal sistemdeki triptofanın çeşitli biyokimyasal reaksiyonlarla indigo ve indirubin pigmentlerine metabolize edilerek idrarda renk değişikliğine neden olduğu belirtilmiştir. İdrar torbasındaki alışılmadık renk değişiminin hasta, hasta yakınları ve sağlık çalışanları için endişe verici olduğu, bu durumun altta yatan üriner enfeksiyonun tedavisi, üriner kateter değişimi ve üriner sanitasyonun sağlanmasıyla düzelebileceğini açıklamışlardır. Bizim olgumuzda da, hastanın konstipasyonu ve üriner sistem enfeksiyonu olması nedeniyle MiTS gelişmiştir.

Kumar ve arkadaşları ${ }^{10} 2018$ yılında biri 56 yaşında meme kanseri yanı sıra çoklu karaciğer ve vertebra metastazları nedeniyle, diğeri 75 yaşında non-Hodgkin lenfoma, parotis bezinde skuamöz hücreli karsinomu ve femur boyun kırığı nedeniyle yatağa bağımlı olan kronik konstipe ve kalıc üriner kateteri olan iki kadın hastada MiTS görüldüğünü belirtmişlerdir. Bu durumun çoklu bakteriyel üriner enfeksiyona; çoğunlukla gram-negatif 
bakterilere bağlı olduğunu açıklamışlardır. P.stuartii, P.rettgeri, P.mirabilis, P.aeruginosa, K. pneumoniae, E.coli, M.morganii, Citrobacter spp., Enterococcus spp. ve B grubu streptokokların idrar kültürlerinden izole edilebileceğini belirtmişlerdir. Olgumuzda, idrar kültüründe E.faecalis tespit edilmiştir.

Ülkemizde de MiTS olgularına rastlanmıştır. Koçoğlu ve arkadaşları ${ }^{5}, 2016$ yılında 78 yaşında benign prostat hiperplazisi nedeniyle kalıcı üriner kateteri olan ve kronik böbrek yetmezliği nedeniyle hemodiyaliz alan erkek hastada MiTS görüldüğünü bildirmişlerdir. Hastanın idrar kültüründe genişletilmiş spektrumlu beta-laktamaz üreten E.coli izole edilmiş olup bu klinik durumun patogenezinde sülfataz ve fosfataz üreten bakterilerin rol oynadığını, kalıcı üriner kateterizasyon, ileri yaş, kadın cinsiyet, dehidratasyon, immobilizasyon, konstipasyon, kronik böbrek yetmezliği, alkali veya asidik idrar, hastaya PVC içeren plastik kateter ve idrar torbası uygulanması gibi risk faktörlerinin yer aldığını belirtmişlerdir. Olgumuzda da altta yatan klinik durumlara ek olarak PVC içeren üriner kateter ve idrar torbası uygulanmasının MiTS'e neden olduğu düşünülmüştür.

Belçika'da 2015 yılında Van Keer ve arkadaşları ${ }^{9}$, anoreksi ve akut böbrek yetmezliği nedeniyle nefroloji kliniğine yatırılan 81 yaşında erkek hastada yatışından bir süre sonra MiTS geliştiğini belirtmişlerdir. Özgeçmişinde miyokard infarktüsü, non-Hodgkin lenfoma ve prostat kanseri öyküsü olan hastanın batınındaki lenfadenopatilerinin üretere bası yapması sonucu böbrekte hidronefroz gelişmesi nedeniyle hastaya nefrostomi uygulanmıştır. Yattığı sürede hastada konstipasyon şikayeti gelişmiş ve nefrostomi idrarının rengi normal iken suprapubik kateterin idrar torbasında mor renk değiş̧ikliği görülmüştür. İdrar kültürlerinde P.aeruginosa ve E.faecalis izole edilen hastanın nefrostomi materyalinin normal renkte olduğunu, idrarın idrar torbasıyla temas ettikten sonra mor renk aldığını belirtmişlerdir. Olgumuzda da önce kırmızı renk değişikliği farkedilmiş olup bir süre sonra idrarın mor renk aldığı görülmüştür. Kırmızı renk değişikliğinin hematüri olduğu düşünülmesine rağmen tam idrar tetkikinde anlamlı hemoglobin ve eritrosit yüksekliği saptanmamıştır. Kırmızı renk değişikliğinin idrarda oluşan indikatörlerin oksitlenmesi sonucu oluşan pigmentlere bağlı olduğu ve iki gün sonra görülen mor renk değişikliğinin ise bu pigmentlerin PVC içeren idrar torbası ile reaksiyon vermesi sonucu olduğu düşünülmüştür.

Olgumuz kronik böbrek yetmezlikli, nörolojik defisiti nedeniyle immobilize, konstipe, ileri yaşta kadın hasta olması nedeniyle literatürdeki olgularla benzer özellikler göstermektedir. Fakat üriner kateterizasyonun ilk kez uygulanması ve E.faecalis izole edilmesi nedeniyle diğer olgulardan farklı özellik göstermektedir.

İdrarda renk değişikliği önemli hastalıkların belirtisi ve ilaç yan etkisi olarak ortaya çıkabilmektedir. Farklı renk değişiklikleri mortalitesi ve morbiditesi yüksek farklı klinik durumlarla ilişkilidir. MiTS, nadir görülmesi ve altta yatan çeşitli patolojik faktörlerden kaynaklanması nedeniyle bilinmesi gereken klinik bir durumdur.

\section{ÇIKAR ÇATIŞMASI}

Yazarlar bu makale ile ilgili herhangi bir çıkar çatışması bildirmemişlerdir. 


\section{KAYNAKLAR}

1. Al Montasir A, Al Mustaque A. Purple urine bag syndrome. J Family Med Prim Care 2013;2(1):104-5.

2. Khan F, Chaudhry MA, Qureshi N, Cowley B. Purple urine bag syndrome: an alarming hue? A brief review of the literature. Int J Nephrol 2011; 2011:419213.

3. Traynor BP, Pomeroy E, Niall D. Purple urine bag syndrome: a case report and review of the literature. Oxf Med Case Reports 2017;2017(11):om×059.

4. Kalsi DS, Ward J, Lee R, Handa A. Purple urine bag syndrome: a rare spot diagnosis. Dis Markers 2017;2017:9131872.

5. Kocoglu H, Yildirim B, Okuturlar Y, Hursitoglu M, Harmankaya O. Purple urine bag syndrome in a male patient with chronic hemodialysis. Balkan Med J 2016;33(6):717-8.

6. Karray O, Batti R, Talbi E, Ayed H, Chakroun M, Ouarda MA, et al. Purple urine bag syndrome, a disturbing urine discoloration. Urol Case Rep 2018;20:57-9.

7. Worku DA. Purple urine bag syndrome: an unusual but important manifestation of urinary tract infection. Case report and literature review. SAGE Open Med Case Rep 2019;7:2050313×18823105.

8. Wang IK, Ho DR, Chang HY, Lin CL, Chuang FR. Purple urine bag syndrome in a hemodialysis patient. Intern Med 2005;44(8):859-61.

9. Van Keer J, Detroyer D, Bammens B. Purple urine bag syndrome in two elderly men with urinary tract infection. Case Rep Nephrol 2015;2015:746981.

10. Kumar D, Donga N, Macwan R. Purple urine bag syndrome: a scary but easily manageable condition in a patient with prolonged indwelling urinary catheter. Indian J Palliat Care 2018;24(4):534-6. 